\title{
Passive Smoking Increases Exposure to Polycyclic Aromatic Hydrocarbons and Leads to Prolonged Lipid Oxidation: Lessons From a Natural Experiment in Travelers From Los Angeles to Beijing
}

Yan Lin

University of California Los Angeles

Yifang Zhu

University of California Los Angeles

Xinghua Qiu

Peking University

Fen Yin

University of California Los Angeles

Chi-Hong Tseng

University of California Los Angeles

Jesus A Araujo ( $\sim$ jaraujo@mednet.ucla.edu )

Division of Cardiology, David Geffen School of Medicine at UCLA, 10833 Le Conte Avenue, CHS 43-264, P.O. Box 951679, Los Angeles, CA 90095. https://orcid.org/0000-0001-8279-8922

\section{Research}

Keywords: Passive smoking, Polycyclic aromatic hydrocarbons, Lipid peroxidation

Posted Date: September 4th, 2020

DOI: https://doi.org/10.21203/rs.3.rs-68389/v1

License: () (1) This work is licensed under a Creative Commons Attribution 4.0 International License. Read Full License 


\section{Abstract}

Background: There are drastic differences in smoking prevalence and control policies among different countries. However, the impact of international travels on passive smoking exposures and subsequent health effects remained unknown.

Methods: We recruited 27 non-smokers who travelled from Los Angeles to Beijing for 10 weeks in 2014 and 2015. Urine samples ( $n=197)$ were collected before (LA-before), during (Beijing), and after (LA-after) the trip, for the assessment of biomarkers of passive smoking (cotinine), PAHs exposure (hydroxylated-PAHs), and lipid peroxidation (malondialdehyde and 8-isoprostane).

Results: The geometric mean concentrations of urinary cotinine were $0.13,1.50$, and $0.22 \mu \mathrm{g} / \mathrm{g}$ creatinine in LA-before, Beijing, and LA-after, respectively. Likewise, hydroxylated-PAH levels were significantly higher in Beijing as compared to LA-before or LA-after $(p<0.001)$, in association with the urinary cotinine concentrations $(p<0.05)$. Traveling from Los Angeles to Beijing increased urinary concentrations of malondialdehyde by $51.8 \%(95 \% \mathrm{Cl}, 29.1 \%$ to $78.5 \%)$, which did not return to baseline levels, up to 4 - 10 weeks after traveling back to Los Angeles. Remarkably, while urinary 8-isoprostane concentrations were similar between Beijing and LA-before, those levels increased by $75.5 \%(95 \% \mathrm{Cl}, 48.5 \%$ to $108 \%)$ after returning to Los Angeles (LA-after), and were significantly higher than baseline (LA-before, $63.6 \% ; 95 \% \mathrm{Cl}, 31.1 \%$ to $104 \%$ ). Urinary concentrations of malondialdehyde and 8-isoprostane were positively associated with urinary cotinine concentrations, independently of hydroxylated-PAHs.

Conclusion: Traveling from Los Angeles to Beijing increased exposures to passive smoking, which contributed to increased PAHs exposures and increased lipid peroxidation in the urine.

Trial Registration: Not applicable.

\section{Background}

Passive smoking refers to involuntary exposures to tobacco smoke that were either exhaled by smokers (secondhand smoke, SHS) or adhered to the surfaces of clothing, hair, furnishings, and dust (thirdhand smoke, THS) (1). Exposure to SHS was prevalent in more than $1 / 3$ of the population worldwide, responsible for 603,000 deaths in $2004,379,000$ of which were due to ischemic heart diseases (2). Although the global burden of disease attributable to THS remains unclear, the exposure to THS is likely to be ubiquitous due to its persistence in the environment (3). Remarkably, passive smoking among local residents at home or workplaces has been found to be higher in developing countries as compared with developed countries (4-6) likely due to higher prevalence of smoking and the lack of regulatory policies in developing countries $(7,8)$. However, it is not known whether differences in smoking prevalence and control policies among different countries could influence passive smoking among travelers, whose activities are mostly outside homes and workplaces.

Cumulative evidence indicates a variety of adverse health effects induced by passive smoking, which are largely attributed to its content of a large number of toxic components (9). To date, over 250 toxic chemicals have been identified in SHS with biological half-lives ranging from milliseconds (free radicals) to years (cadmium) (9), some of which could react with gaseous pollutants leading to the formation of even more toxic products in THS (1). Of note, polycyclic aromatic hydrocarbons (PAHs), a group of toxic byproducts of incomplete combustions, have been thought to exert significant effects on the health of passive smokers. Similar to SHS exposures, previous studies have shown that people in developing countries are subjected to higher exposures to PAHs as well (10). However, it remains unclear to what extent, the elevated PAHs exposures in developing countries are due to passive smoking or other sources such as air pollution.

The United States (U.S.) and China are among the world's largest developed and developing countries, respectively. The number of residences traveling between both countries increased rapidly in recent years, reaching 1.31 and 2.59 million in the U.S and China in 2015, respectively (11). In our previous studies, we have identified a marked increase in the levels of PAH metabolites in urines of healthy young adults who traveled from Los Angeles to Beijing for a 10-week period in 2014 and 2015, 
which indicated a significant increase in the exposure to PAHs $(12,13)$. Furthermore, we observed significant increases in circulating biomarkers of lipid peroxidation after the participants spent 6-8 weeks in Beijing, which reversed almost completely 4-7 weeks after the participants returned to Los Angeles, and were positively associated with the urinary levels of PAHs metabolites (12). However, because only one blood sample was collected from each participant at each phase (i.e. before, during, or after the travel), the dynamics of the pro-oxidative changes and their reversibility in response to changes in PAHs exposures could not be determined.

Compared with blood collection, the analysis of urinary biomarkers causes less burden to human subjects when studying the dynamics of oxidative changes in response to environmental pollution. However, it is not certain whether lipid peroxidation detected in the urine derives from the clearance of oxidation products circulating in the blood, oxidation in the actual kidney tissues or both. Importantly, the ability of passive smoking to induce lipid peroxidation in kidney tissues has been well documented in previous studies (14). Furthermore, some redox-active constituents in tobacco smoke mixtures (e.g. cadmium) have been shown to accumulate in the kidney over years (15), and it is unclear whether passive smoking exposures could cause lipid peroxidation in the kidneys even after the exposure cessation.

With the higher population density and prevalence of smoking in China (16), residents from Los Angeles traveling to Beijing would be expected to encounter increased passive smoking. In this study, we analyzed the levels of cotinine, PAH metabolites (OH-PAHs), malondialdehyde (MDA), and 8-isoprostane in 197 urine samples collected from 27 residents of Los Angeles before, during, and after their 10-week stay in Beijing in 2014 and 2015, aiming to determine (i) changes in passive smoking when traveling from Los Angeles to Beijing; (ii) to what extent passive smoking could mediate the changes in PAHs exposures during the travel; and (iii) whether changes in passive smoking could alter the degree of lipid peroxidation in the urine.

\section{Results}

Demographic characteristics. The mean (SD) age was 25.4 (10.3) years and mean (SD) BMI was $21.5(2.4) \mathrm{kg} / \mathrm{m}^{2}$ in the 27 study participants (15 females and 12 males) (Table S1). All participants were non-smokers and most of them were healthy Asian young adults. One participant was self-reported to have hypertension. No participants were recorded with any heart disease, metabolic disorder, kidney disease, blood coagulation disorders, rheumatological disease or chronic inflammation. Urine samples were collected from 23 participants in all three phases while samples of four participants were not collected in either LA-before $(n=3)$ or LA-after $(n=1)$.

Passive smoking exposures. The urinary cotinine was detected in all samples collected in Beijing but only in $78.6 \%$ of those in Los Angeles. The geometric mean concentration of urinary cotinine was 1.50 (IQR: $0.87-2.21) \mu \mathrm{g} / \mathrm{g}$ creatinine in Beijing, significantly higher $(p<0.001)$ than that in LA-before (geometric mean: 0.13 ; IQR: $0.06-0.24 \mu \mathrm{g} / \mathrm{g}$ creatinine) or LA-after (geometric mean: 0.22; IQR: 0.09-0.40 $\mu \mathrm{g} / \mathrm{g}$ creatinine) (Table 1). This trend was consistent in both 2014 (Fig. 1A) and 2015 (Fig. 1B). Correspondingly, 52.5\% of urine samples in Beijing were collected after participants had spent time near smokers in the past three days, markedly higher than the frequencies in LA-before $(2.9 \%)$ or LA-after (3.2\%). All this data indicates elevated passive smoking exposures in Beijing. 
Table 1

Descriptive statistics of urinary biomarkers in Beijing and Los Angeles before (LA-before) and after the trip (LA-after)

\begin{tabular}{|c|c|c|c|c|c|c|}
\hline & \multicolumn{3}{|c|}{ geometric mean (IQR) ${ }^{a}$} & \multicolumn{3}{|c|}{$p$-value for the difference ${ }^{b}$} \\
\hline & $\begin{array}{l}\text { in LA-before ( } \\
=35)\end{array}$ & $\begin{array}{l}\text { in Beijing }(n= \\
99)\end{array}$ & $\begin{array}{l}\text { in LA-after (n } \\
=63 \text { ) }\end{array}$ & $\begin{array}{l}\text { Beijing vs. LA- } \\
\text { before }\end{array}$ & $\begin{array}{l}\text { Beijing vs. } \\
\text { LA-after }\end{array}$ & $\begin{array}{l}\text { LA-before vs. } \\
\text { LA-after }\end{array}$ \\
\hline Creatinine & $\begin{array}{l}1418(1089- \\
2190)\end{array}$ & $\begin{array}{l}1511(1143- \\
2298)\end{array}$ & $\begin{array}{l}1415(970- \\
2244)\end{array}$ & 0.37 & 0.27 & 0.99 \\
\hline Cotinine & $\begin{array}{l}0.13(0.06- \\
0.24)\end{array}$ & $\begin{array}{l}1.50(0.87- \\
2.21)\end{array}$ & $\begin{array}{l}0.22(0.09- \\
0.40)\end{array}$ & $<0.001$ & $<0.001$ & 0.03 \\
\hline $\begin{array}{l}\triangle \mathrm{OH}- \\
\text { NAPs }\end{array}$ & $\begin{array}{l}2.59(1.64- \\
3.36)\end{array}$ & $\begin{array}{l}3.58(2.31- \\
4.96)\end{array}$ & $\begin{array}{l}3.49(1.87- \\
5.86)\end{array}$ & 0.08 & 0.84 & 0.07 \\
\hline 2-OH-DBF & $\begin{array}{l}0.13(0.08- \\
0.19)\end{array}$ & $\begin{array}{l}1.10(0.81- \\
1.59)\end{array}$ & $\begin{array}{l}0.14(0.11- \\
0.22)\end{array}$ & $<0.001$ & $<0.001$ & 0.45 \\
\hline هOH-FLUs & $\begin{array}{l}0.20(0.12- \\
0.35)\end{array}$ & $\begin{array}{l}1.21(0.90- \\
1.70)\end{array}$ & $\begin{array}{l}0.28(0.19- \\
0.34)\end{array}$ & $<0.001$ & $<0.001$ & 0.01 \\
\hline 『OH-PHEs & $\begin{array}{l}0.39(0.27- \\
0.61)\end{array}$ & $\begin{array}{l}1.35(1.01- \\
1.88)\end{array}$ & $\begin{array}{l}0.51(0.38- \\
0.70)\end{array}$ & $<0.001$ & $<0.001$ & 0.008 \\
\hline 1-OH-PYR & $\begin{array}{l}0.07(0.04- \\
0.29)\end{array}$ & $\begin{array}{l}0.20(0.14- \\
0.29)\end{array}$ & $\begin{array}{l}0.12(0.07- \\
0.17)\end{array}$ & $<0.001$ & $<0.001$ & 0.002 \\
\hline \multicolumn{7}{|c|}{ a. unit: $\mu \mathrm{g} / L$ for creatinine; $\mu \mathrm{g} / \mathrm{g}$ creatinine for the others } \\
\hline
\end{tabular}

To our surprise, the cotinine concentration in urine collected from participants who reported to spend time near smokers in Beijing ( $n=51$ ) was comparable with those who didn't ( $n=48, p=0.66$, Figure S1). Consistently, we observed no associations between urinary cotinine concentrations and self-reported time near smokers after controlling for phase, year, and other activities ( $p=0.92$, Table S2). No associations were observed between cotinine levels and time spent in Beijing or LA-after (Figs. 1C and 1D).

Associations between passive smoking and PAHs exposures. All OH-PAHs analytes were detected in at least $94.6 \%$ of samples. Similar to the changes in urinary cotinine levels, traveling from Los Angeles to Beijing led to significant increases in

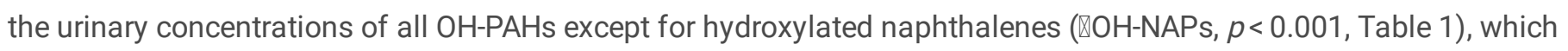
reversed, at least partially, after participants returned to Los Angeles. Of note, the concentrations of most OH-PAHs and cotinine in LA-after were significantly higher as compared with LA-before $(p<0.05)$; however, the differences between LAbefore and LA-after were much smaller than the differences between the two cities. These results strongly suggest that participants were subjected to elevated exposures to PAHs in Beijing.

The urinary levels of cotinine were significantly associated with the concentrations of hydroxylated phenanthrenes $(\mathbb{O H}-$ PHEs) and 1-hydroxylated pyrene (1-OH-PYR) $(p<0.001)$ in the urine, but not with the other OH-PAHs (Table 2). On the other hand, time spent on barbecuing activities and public transportation was positively associated with OH-PAHs $(p<0.05)$, suggesting that behavioral changes related to diet and outdoor air pollution could have also influenced the exposure to PAHs. Since both cotinine concentrations and time spent in public transportation were markedly increased from Los Angeles to Beijing (Table S3), it is likely that both passive smoking and behavioral changes contributed to higher exposure to PAHs in Beijing. Remarkably, the concentrations of 2-hydroxylated dibenzofuran (2-OH-DBF), hydroxylated fluorenes ( $\nabla \mathrm{OH}-\mathrm{FLUs})$, and $\triangle \mathrm{OH}-\mathrm{PHEs}$ remained significantly higher in Beijing than in LA-before even after adjusting for urinary cotinine concentrations and behavioral changes (Table 2), which may reflect the effects of the more severe air pollution in Beijing as previously reported (12). 
Table 2

Determinants of logarithmic urinary $\mathrm{OH}-\mathrm{PAHs}$ concentrations in multivariable mixed-effect model with random intercepts of study participant (, SE, and p-value were estimated in full models including all variables)

\begin{tabular}{|c|c|c|c|c|c|c|c|c|c|c|}
\hline \multicolumn{11}{|l|}{$\beta$} \\
\hline \multirow[t]{2}{*}{ Variables } & \multicolumn{2}{|c|}{ 囚OH-NAP } & \multicolumn{2}{|c|}{ 2-OH-DBF } & \multicolumn{2}{|c|}{ 『OH-FLUs } & \multicolumn{2}{|c|}{$\triangle \mathrm{OH}-\mathrm{PHE}$} & \multicolumn{2}{|c|}{ 1-OH-PYR } \\
\hline & $\beta(\mathrm{SE})$ & $\begin{array}{l}p- \\
\text { value }\end{array}$ & $\beta(\mathrm{SE})$ & $\begin{array}{l}p- \\
\text { value }\end{array}$ & $\beta(S E)$ & $\begin{array}{l}p- \\
\text { value }\end{array}$ & $\beta(\mathrm{SE})$ & $\begin{array}{l}p- \\
\text { value }\end{array}$ & $\beta(\mathrm{SE})$ & $\begin{array}{l}p- \\
\text { value }\end{array}$ \\
\hline $\begin{array}{l}\log _{10} \\
\text { cotinine }\end{array}$ & $\begin{array}{l}0.11 \\
(0.06)\end{array}$ & 0.10 & $\begin{array}{l}-0.01 \\
(0.06)\end{array}$ & 0.86 & $\begin{array}{l}0.07 \\
(0.05)\end{array}$ & 0.19 & $\begin{array}{l}0.18 \\
(0.05)\end{array}$ & $\hat{0} .001$ & $\begin{array}{l}0.25 \\
(0.06)\end{array}$ & $\begin{array}{l}< \\
0.001\end{array}$ \\
\hline $\begin{array}{l}\log _{10} \\
\text { cotinine } \times \text { City } \\
(\text { Beijing }=1)\end{array}$ & $\begin{array}{l}0.06 \\
(0.11)\end{array}$ & 0.62 & $\begin{array}{l}0.15 \\
(0.11)\end{array}$ & 0.19 & $\begin{array}{l}0.01 \\
(0.09)\end{array}$ & 0.94 & $\begin{array}{l}-0.05 \\
(0.09)\end{array}$ & 0.58 & $\begin{array}{l}-0.20 \\
(0.11)\end{array}$ & 0.06 \\
\hline $\begin{array}{l}\text { Beijing vs. LA- } \\
\text { before }\end{array}$ & $\begin{array}{l}0.01 \\
(0.10)\end{array}$ & 0.96 & $\begin{array}{l}1.00 \\
(0.10)\end{array}$ & <. 001 & $\begin{array}{l}0.68 \\
(0.09)\end{array}$ & $\hat{0} .001$ & $\begin{array}{l}0.45 \\
(0.08)\end{array}$ & $\hat{0} .001$ & $\begin{array}{l}0.09 \\
(0.10)\end{array}$ & 0.39 \\
\hline $\begin{array}{l}\text { LA-after vs. } \\
\text { LA-before }\end{array}$ & $\begin{array}{l}0.10 \\
(0.06)\end{array}$ & 0.11 & $\begin{array}{l}0.08 \\
(0.06)\end{array}$ & 0.18 & $\begin{array}{l}0.14 \\
(0.05)\end{array}$ & 0.008 & $\begin{array}{l}0.12 \\
(0.05)\end{array}$ & 0.01 & $\begin{array}{l}0.14 \\
(0.06)\end{array}$ & 0.02 \\
\hline $\begin{array}{l}\text { Year (2015 vs. } \\
2014)\end{array}$ & $\begin{array}{l}-0.09 \\
(0.10)\end{array}$ & 0.37 & $\begin{array}{l}0.08 \\
(0.07)\end{array}$ & 0.26 & $\begin{array}{l}0.06 \\
(0.07)\end{array}$ & 0.43 & $\begin{array}{l}0.19 \\
(0.06)\end{array}$ & 0.002 & $\begin{array}{l}-0.01 \\
(0.08)\end{array}$ & 0.87 \\
\hline $\begin{array}{l}\text { Year } \times \text { City } \\
\text { (Beijing in } \\
2015=1 \text { ) }\end{array}$ & $\begin{array}{l}-0.13 \\
(0.09)\end{array}$ & 0.15 & $\begin{array}{l}-0.30 \\
(0.08)\end{array}$ & <. 001 & $\begin{array}{l}-0.20 \\
(0.07)\end{array}$ & 0.008 & $\begin{array}{l}-0.15 \\
(0.07)\end{array}$ & 0.03 & $\begin{array}{l}-0.04 \\
(0.08)\end{array}$ & 0.60 \\
\hline $\begin{array}{l}\text { Time in } \\
\text { cooking (h) }\end{array}$ & $\begin{array}{l}0.01 \\
(0.02)\end{array}$ & 0.53 & $\begin{array}{l}-0.01 \\
(0.02)\end{array}$ & 0.61 & $\begin{array}{l}-0.03 \\
(0.02)\end{array}$ & 0.04 & $\begin{array}{l}-0.01 \\
(0.01)\end{array}$ & 0.63 & $\begin{array}{l}-0.02 \\
(0.02)\end{array}$ & 0.20 \\
\hline $\begin{array}{l}\text { Time in } \\
\text { barbecuing } \\
\text { (h) }\end{array}$ & $\begin{array}{l}0.16 \\
(0.06)\end{array}$ & 0.005 & $\begin{array}{l}0.10 \\
(0.06)\end{array}$ & 0.08 & $\begin{array}{l}0.11 \\
(0.05)\end{array}$ & 0.02 & $\begin{array}{l}0.18 \\
(0.05)\end{array}$ & $\hat{0} .001$ & $\begin{array}{l}0.27 \\
(0.06)\end{array}$ & $\hat{0} .001$ \\
\hline $\begin{array}{l}\text { Barbecue } \\
\text { intake (kg) }\end{array}$ & $\begin{array}{l}-0.20 \\
(0.07)\end{array}$ & 0.006 & $\begin{array}{l}-0.01 \\
(0.07)\end{array}$ & 0.94 & $\begin{array}{l}-0.01 \\
(0.06)\end{array}$ & 0.87 & $\begin{array}{l}-0.13 \\
(0.06)\end{array}$ & 0.02 & $\begin{array}{l}-0.16 \\
(0.07)\end{array}$ & 0.02 \\
\hline $\begin{array}{l}\text { Baked food } \\
\text { intake }(\mathrm{kg})\end{array}$ & $\begin{array}{l}-0.02 \\
(0.02)\end{array}$ & 0.29 & $\begin{array}{l}-0.01 \\
(0.02)\end{array}$ & 0.63 & $\begin{array}{l}-0.02 \\
(0.02)\end{array}$ & 0.40 & $\begin{array}{l}-0.03 \\
(0.02)\end{array}$ & 0.06 & $\begin{array}{l}-0.01 \\
(0.02)\end{array}$ & 0.51 \\
\hline $\begin{array}{l}\text { Driving time } \\
\text { (h) }\end{array}$ & $\begin{array}{l}0.00 \\
(0.01)\end{array}$ & 0.97 & $\begin{array}{l}-0.03 \\
(0.01)\end{array}$ & 0.005 & $\begin{array}{l}-0.00 \\
(0.01)\end{array}$ & 0.76 & $\begin{array}{l}-0.01 \\
(0.01)\end{array}$ & 0.27 & $\begin{array}{l}-0.01 \\
(0.01)\end{array}$ & 0.66 \\
\hline $\begin{array}{l}\text { Time near } \\
\text { heavy traffic } \\
\text { (h) }\end{array}$ & $\begin{array}{l}0.01 \\
(0.02)\end{array}$ & 0.74 & $\begin{array}{l}-0.00 \\
(0.02)\end{array}$ & 0.80 & $\begin{array}{l}-0.01 \\
(0.01)\end{array}$ & 0.27 & $\begin{array}{l}-0.01 \\
(0.01)\end{array}$ & 0.66 & $\begin{array}{l}-0.01 \\
(0.02)\end{array}$ & 0.46 \\
\hline $\begin{array}{l}\text { Time in public } \\
\text { transportation } \\
\text { (h) }\end{array}$ & $\begin{array}{l}0.01 \\
(0.01)\end{array}$ & 0.45 & $\begin{array}{l}0.02 \\
(0.01)\end{array}$ & 0.10 & $\begin{array}{l}0.04 \\
(0.01)\end{array}$ & $\begin{array}{l}< \\
0.001\end{array}$ & $\begin{array}{l}0.01 \\
(0.01)\end{array}$ & 0.18 & $\begin{array}{l}0.03 \\
(0.01)\end{array}$ & 0.004 \\
\hline $\begin{array}{l}\text { Time near } \\
\text { smokers }(\mathrm{h})\end{array}$ & $\begin{array}{l}0.00 \\
(0.02)\end{array}$ & 0.94 & $\begin{array}{l}-0.01 \\
(0.02)\end{array}$ & 0.59 & $\begin{array}{l}-0.01 \\
(0.01)\end{array}$ & 0.61 & $\begin{array}{l}-0.01 \\
(0.01)\end{array}$ & 0.48 & $\begin{array}{l}0.00 \\
(0.02)\end{array}$ & 0.80 \\
\hline
\end{tabular}

Biomarkers of lipid peroxidation. MDA is a lipid peroxidation product via both enzymatic and non-enzymatic pathways, while 8-isoprostane is more specific to non-enzymatic pathways. We observed significant increases in urinary concentrations of MDA in Beijing ( $p<0.001$, Fig. 2A). However, unlike urinary OH-PAHs and cotinine, the increase in MDA concentration in Beijing did not return to baseline levels after the participants returned to Los Angeles (LA-after, Fig. 2A). To our surprise, the concentration of 8-isoprostane did not increase in Beijing but instead, it increased after returning to Los Angeles (LA-after) as compared with levels in LA-before or in Beijing ( $p<0.001$, Fig. 2B). Interestingly, the concentrations of 8-isoprostane but not MDA significantly decreased over time $(p<0.001)$ while participants were in Beijing (Figs. $2 \mathrm{C}$ and 2D). The decrease in 8isoprostane in Beijing over time could not be due to changes in PAHs exposures, which instead, they were likely to increase 
over time as judged by increases in OH-PAHs concentrations (Figure S2). Participants' time spent in LA-after was not associated with urinary concentrations of MDA (Fig. 2E) or 8-isoprostane (Fig. 2F).

Associations between passive smoking and lipid peroxidation We found that one-fold increase in urinary cotinine concentrations were associated with $9.54 \%$ (95\% Cl: 4.88 to $14.4 \%)$ and $8.42 \%$ (95\% Cl: 2.03 to 15.3\%) increases in the concentrations of MDA (Fig. 3A) and 8-isoprotane (Fig. 3B), respectively. Likewise, urinary OH-PAHs concentrations were positively associated with both MDA and 8-isoprostane concentrations as well (Figure S3). Adjusting for OH-PAHs concentrations didn't annihilate the association of urinary cotinine with MDA and 8-isoprostane concentrations (Figs. 3A and 3B), and vice versa (Figure S3). Given the short half-time of cotinine and PAHs in human body (i.e. several hours) $(17,18)$, these associations suggested that short-term exposures to passive smoking and PAHs were independently associated with lipid peroxidation.

We calculated the average concentrations of urinary cotinine in each phase as a proxy to accumulated exposures to passive smoking. We found that the difference in average 8-isoprostane concentrations between LA-after and LA-before was significantly associated with the average cotinine concentration in Beijing $(p<0.05$, Fig. $3 C)$, but not with the cotinine concentration in LA-after (Fig. 3D), indicating that the pro-oxidative effects of passive smoking in Beijing persisted even after participants returned to Los Angeles. In contrast, the difference in 8-isoprostane concentrations between LA-after and LAbefore was significantly associated with OH-PAHs concentrations in LA-after $(p<0.05)$, but not with those in Beijing (Figure S4). This is consistent with the short half-lives of PAHs in human body of less than one day as suggested previously $(17,18)$.

\section{Discussion}

We have found in this study that traveling to a country with a high prevalence of smoking results not only in increased exposures to passive smoking but also in the induction of significant health effects, long after the exposures have concluded. This is the first study focusing on the risk of passive smoking among a ubiquitous but underappreciated population international travelers, of whom the exposure duration is likely to be different from local residents.

We followed 27 travelers between Los Angeles and Beijing and found significantly higher exposures to passive smoking in Beijing, in association with elevated exposures to PAHs, and increased lipid peroxidation in the urine. These results indicate that cross-boundary traveling could change the degree of passive smoking exposures, which may contribute to elevated exposures to toxic chemicals and subsequently, the development of adverse health effects that could promote cardiovascular diseases. In addition, our findings may also inform on potential risks associated to passive smoking exposures among local residences in Beijing, China.

Nicotine is metabolized by cytochromes P450 into cotinine and excreted from human bodies by the kidney (19), reasoning why the urinary concentration of cotinine has been widely employed as a biomarker of exposure to passive smoking in population studies $(17,20)$. In the current study, we collected multiple urine samples for each participant with intervals of at least one week, which is much longer than cotinine's half-time of several hours (17). We observed elevated cotinine levels in urine samples collected at different time points in Beijing as compared with Los Angeles (Figure S5), indicating ubiquitous exposures to passive smoking in Beijing among participants. We initially hypothesized that increased passive smoking exposures in Beijing were mostly attributable to SHS since none of the participants were active smokers and they reported longer time near smokers when in Beijing as compared to when in Los Angeles (Table S3). However, we observed that participants who did not report to be near a smoker before the sample collection in Beijing also exhibited elevated cotinine levels in the urine (Figure S2), which might suggest a significant contribution from THS as well. Nevertheless, we cannot exclude the possibility of recall bias or that participants were exposed to SHS unconsciously.

It has been well documented that tobacco smoke is rich in PAHs (21). Passive smoking is potentially a marked contributor to PAHs exposures (22) since smoking mostly occurs near the general population. In this study, we found that urinary cotinine concentrations were associated with $₫ \mathrm{OH}-\mathrm{PHEs}$ and 1-OH-PYR concentrations $(p<0.001$, Table 2$)$, indicating that passive smoking was likely an important determinant of PAHs exposures among the study participants. On the other hand, the levels 
of 2-OH-DBF, $\triangle \mathrm{OH}-\mathrm{FLU}$ and $\varangle \mathrm{OH}-\mathrm{PHEs}$ were not only significantly higher in Beijing as compared with LA-before but also, they remained as such after adjusting for urinary cotinine concentrations (Table 2), suggesting that other factors contribute to the increase in PAHs exposure in Beijing such as air pollution (12). Indeed, previous studies have reported a 32.7-fold difference in the annual average concentration of airborne non-naphthalene PAHs between Los Angeles $\left(6.67 \mathrm{ng} / \mathrm{m}^{3}\right)(23)$ and Beijing $\left(218 \mathrm{ng} / \mathrm{m}^{3}\right)$ (24). Albeit diet ingestion has been suggested as the major exposure route of PAHs with < = four rings (e.g. 1-OHPYR) (25-27), we don't believe diet played a major role in our study. This is because (i) dietary habits were similar in each study participant while in both cities (Table S3); (ii) samples were collected after 8-h fasting which decreased the influence of diet; and (iii) the PAHs concentration in food has been comparable between China and the U.S. $(26,28)$.

We have previously shown that traveling from Los Angeles to Beijing led to significant increases in circulating levels of oxidized polyunsaturated fatty acids via enzymatic pathways (e.g. lipoxygenases) 6 to 8 weeks after initiating the travel, while the increase in circulating 8-isoprostane concentrations was only borderline significant (12). Likewise, we have observed significant increases in urinary concentrations of MDA, a lipid peroxidation product from both enzymatic and non-enzymatic pathways, after traveling, which remained elevated throughout the whole stay in Beijing and after returning to Los Angeles (Fig. 2A). On the other hand, there were no significant changes in the concentration of 8-isoprostane, which primarily originates from non-enzymatic oxidation of arachidonic acid, in Beijing as compared with LA-before (Fig. 2B). In particular, we observed a progressive decrease in urinary 8-isoprostane levels after participants arriving at Beijing (Fig. 2D) even though there were no decreases in urinary concentrations of cotinine (Fig. 1C) or OH-PAHs (Figure S2) during the stay in Beijing. Indeed, we have observed higher circulating levels of uric acid, pyroglutamic acid, and taurine in Beijing (data not shown) which might reflect participants' enhanced capacity to scavenge free radicals in the circulation.

Surprisingly, however, 8-isoprostane concentrations increased after returning to Los Angeles and remained elevated $>70$ days after (Fig. 2B), which was consistent across different years and different time points (Figure S5). These results are also consistent with the study of Wu et al who observed in nine volunteers traveling from Germany to China for 8-42 days that they exhibited elevated urinary 8-isoprostane levels, at least four weeks after returning to Germany (29). In addition, urinary MDA concentrations in LA-after remained higher than the baseline level as well (Fig. 2A) in contrast to our previous observation among the same participants that oxidized lipids in the circulating blood, returned to baseline after coming back to Los Angeles (12). The discrepancy between urinary and circulating oxidative biomarkers suggested that elevated urinary levels of MDA and 8-isoprostane in LA-after may reflect oxidation at the organ level (e.g. kidney) instead of the systemic circulation. Remarkably, we observed positive associations between average cotinine levels in Beijing and the increase in 8isoprostane levels from LA-before to LA-after (Fig. 3C), suggesting that the pro-oxidative effects of passive smoking exposures in Beijing may persist 4-10 weeks after returning to Los Angeles.

The prolonged detection of increased oxidized lipids in the urine is very important since lipid peroxidation has been shown to play a critical role in the pathogenesis of SHS-induced diseases, including those of cardiovascular nature (30). Thus, previous animal studies have shown that tobacco smoke exposure may induce kidney oxidative damages (31). Of interest, we have noted in our study that the pro-oxidative effects of passive smoking could occur at different time scales likely due to the wide range of biological half-lives from different chemicals in the tobacco smoke mixtures. On one hand, urinary cotinine levels, an indicator of recent exposures, were associated with MDA and 8-isoprostane levels, suggesting marked acute pro-oxidative effects of passive smoking, which has been shown to contain redox-active chemicals with short biological half-lives, such as free radicals, aldehydes, peroxides, and epoxides (32). On the other hand, the average cotinine concentrations in Beijing were correlated with the difference in average 8-isoprostane levels between LA-after and LA-before (Fig. 3C). The persistent effects might be attributed to tobacco smoke components with long half-lives such as cadmium, which has been shown to accumulate in the kidney with a clearance half-life of 25 years (15). Additionally, the slow translocation of cadmium from circulation to organs (half-life $=75-128$ days) (15) may also explain why urinary 8-isoprostane was not increased until participants returned to Los Angeles.

The concentrations of urinary cotinine in Los Angeles and Beijing in this study were in the same magnitude of other nonsmoking population studies from 20 countries (Table S4) (20,33-36). Thus, the level of urinary cotinine in Los Angeles (LA- 
before + LA-after) was at lower levels compared with that in studies from other countries (Table S4) (20). In contrast, urinary cotinine in Beijing was at a relatively higher levels, and it was comparable with levels in studies from Korea and several Europe countries (e.g. Portugal and Hungry) $(20,35)$ but markedly lower that the levels in an Italian Study $(36)$. It is likely that the higher urinary cotinine concentration observed in Beijing was due to a higher prevalence of smoking (30.2\%) (37) as compared with Los Angeles (14.3\%) (38), together with the markedly higher population density in Beijing (4,700 persons $\left.\mathrm{km}^{-2}\right)$ as compared to that in Los Angeles (2,300 persons $\mathrm{km}^{-2}$ ) (39). Indeed, we have noted a significant association between the smoking prevalence of different countries in 2012 (40) and the urinary cotinine level in people participating in studies from 22 countries (20 from other studies and two from the current study) ( $r=0.44, p<0.05$, Figure S6), supporting the logical assumption that increased prevalence of smoking leads to increased exposures to passive smoking. Although previous studies have documented large variabilities in the level of passive smoking exposures among local residents, the latter depended on whether there were active smokers in their families or working places $(41,42)$. The travelers in our study, however, were more likely exposed to passive smoking outside home and in their workplaces, given positive associations between urinary cotinine levels and self-reported driving time (Table S2). Indeed, nicotine has been detected in the air of 44 public places tested in a previous study (e.g. hospitals, secondary schools and restaurants) with a median concentration of $3.0 \mu \mathrm{g} / \mathrm{m}^{3}$ (43). This level is comparable to that of smoking-permitted workplaces in the U.S. and might cause notable passive smoking exposures among visitors to those places (44).

Importantly, exposures to passive smoking can be decreased by regulatory policies targeting active smoking. Thus, effective June 2015, the Beijing government banned smoking in all the indoor areas of public places, including workplaces and public transportation as well as outdoor areas of schools and hospitals (45). Our data obtained in Beijing, in the summers of 2014 and 2015 reflect passive smoking exposures before and after the ban policy, respectively. Although urinary cotinine concentrations and self-reported time near smokers were higher in Beijing than in Los Angeles in both 2014 and 2015, we observed trends towards decreased exposures in Beijing from 2014 to 2015 as evidenced by decreased urinary cotinine concentrations (geometric mean in a unit of $\mu \mathrm{g} / \mathrm{g}$ creatine: 1.68 in 2014 and 1.21 in 2015, respectively), and decreased selfreported time near smokers (Table S3). These data suggest positive effects, likely derived from the implementation of the regulatory policy; however, we cannot exclude the possibility that the trend was dominated by differences in study participants between 2014 and 2015, given significant associations of urinary cotinine concentrations with year $(p<0.05)$, but not with the interaction between year and city (Table S2).

\section{Strengths And Limitations}

In this natural experiment, we performed repeated measurements among the same travelers, allowing each participant to serve as his/her own control. The built-in "cross-over" feature (i.e. from LA-before to Beijing vs. from Beijing to LA-after) allowed us to control the effects due to travel itself and the exposures during the flights. Thus, the observed changes in biomarker concentrations were most likely attributable to the exposures in each city. Despite these strengths, our study has several limitations. First, the small group of travelers in this study may not be representative of either foreign visitors to China or local residents. Second, while our study clearly identified health effects associated to passive smoking exposures among an underappreciated population - travelers, it is unclear whether traveling to other cities with high prevalence of smoking would induce similar effects. Third, changes in urinary concentration levels of cotinine depend not only on the exposure degree to passive smoking, as determined in here, but also on the activity of inducible cytochromes P450 responsible for nicotine metabolism (19), which was not assessed in our study. Finally, the locations where exposures occurred was unclear since we did not measure ambient levels of nicotine in the different microenvironments. While future studies are warranted to address these limitations and shortcomings, our results are relevant in the design of policies aimed at reducing passive smoking exposures.

\section{Conclusions}

Healthy young adults traveling from Los Angeles to Beijing were inadvertently exposed to elevated levels of tobacco smoke, which was associated with increased exposure to PAHs in the destination city and prolonged lipid peroxidation in the urine, 
induced several weeks after returning to the origin city. Future studies are needed to better understand the associated health effects and risk for development of cardiovascular diseases as well as the impact of regional differences in smoking control on exposures to passive smoking among travelers.

\section{Methods}

Study Participants. The study is based on a summer research program between Peking University (PKU) and University of California, Los Angeles (UCLA), in which students from UCLA visit PKU and stay there for 10 weeks in each summer (12, 13, 46). All participants in this study $(n=27)$ were recruited in 2014 or 2015 (12). Demographic information and written informed consent were obtained from all participants with study purpose and risk explained.

Sample Collection. For each participant, up to nine urine samples were collected before the travel (LA-before), in Beijing (2 to 10 weeks after arrival in Beijing), and 4 to 10 weeks after returning to Los Angeles (LA-after). Because PAHs and nicotine are metabolized and excreted rapidly with a half-life less than one day $(17,18)$, each urine was collected at least one week after the previous collection. Each urine collection was coupled with a questionnaire survey that included time spent near smokers in the past three days, and various activities related to PAHs exposures in the past three days, such as (i) cooking behaviors (time for cooking and barbecuing), (ii) dietary intakes of food rich in PAHs (consumption of barbecue or baked food), and (iii). traffic-related behaviors (driving hours, public transportation usage, and time spent near heavy traffic).

Laboratory Analysis. We used a gas chromatograph and mass spectrometer (GC-MS; Agilent 7890A-5975C) with a isotope dilution method to measure the concentration of cotinine and 11 hydroxylated PAHs in the urine including 1- and 2-OH-NAPs, 2-OH-DB), 2- and 3-OH-FLUs, 1-, 2-, 3-, 4- and 9-OH-PHEs and 1-OH-PYR. To determine urinary cotinine, $0.5 \mathrm{~mL}$ urine was spiked with deuterium-labeled (+/-)-cotinine and alkalinized with $0.5 \mathrm{~mL} \mathrm{NaOH}(4 \mathrm{M}) / \mathrm{KCl}(1 \mathrm{M})$ solution. The aliquant was then extracted with $2 \mathrm{~mL}$ dichloromethane four times and concentrated under nitrogen flow for instrumental analysis. To determine urinary $\mathrm{OH}-\mathrm{PAHs}$, after spiked with deuterium- or ${ }^{13} \mathrm{C}$ - labeled hydroxylated PAHs (i.e. ${ }^{13} \mathrm{C}_{6}-2-\mathrm{OH}-\mathrm{NAP},{ }^{13} \mathrm{C}_{6}-3-\mathrm{OH}-\mathrm{FLU},{ }^{13} \mathrm{C}_{6}-3-\mathrm{OH}-$ $\mathrm{PHE}$ and $\mathrm{d}_{9}-1-\mathrm{OH}-\mathrm{PYR}$ ) as surrogate standards, $2 \mathrm{~mL}$ of urine was incubated with $\beta$-glucurnonidase-sulfatase (Helix pomatia, Sigma-Aldrich, St. Louis, MO), followed by liquid-liquid extraction, diazomethane derivation, purification by column chromatography and instrumental analysis. Two OH-NAPs and two OH-PHEs (i.e. 3-OH-PHE, 9-OH-PHE) could not be distinctly separated in chromatograms; therefore, their summed concentrations were reported as $₫ \mathrm{OH}-\mathrm{NAPs}$ and $3+9-\mathrm{OH}-\mathrm{PHEs}$, respectively. The concentration of 2-OH-DBF was corrected by ${ }^{13} \mathrm{C}_{6}-3-\mathrm{OH}-\mathrm{FLU}$, while other analytes were corrected by corresponding surrogate standards. After correction, the recovery of all analytes in spiked samples was $99.6 \pm 7.6 \%$ (range 85.2-110.7\%), and the relative standard deviation was $7.6 \pm 4.3 \%$ (range 2.6-15.7\%). Blank samples were prepared for each eight urine samples, and negligible contamination was observed for all analytes. Concentrations of metabolites from the same PAHs were summed as an exposure indicator for the parent compound.

Urinary creatinine was measured by a spectrophotometer under a wavelength of $510 \mathrm{~nm}$ based on the Jaffe reaction (47). Urinary MDA concentrations were measured by a high-performance liquid chromatograph (HPLC; Waters2695) coupled with a UV detector under a wavelength of $532 \mathrm{~nm}$, after the reaction with 2-thiobarbituric acid (TBA). Urinary 8-isoprostane was measured with a commercial ELISA kit (R\&D, Detroit, MI) according to the manufacturer's instructions. Each urine sample was analyzed in duplicate. All urinary biomarkers were normalized by creatinine, unless noted otherwise, to reduce interferences of diluted/concentrated spot urine samples.

Statistical Analysis. Analytes not detected in urine samples were substituted with $1 / 2$ limit of quantification (LOQ) for statistical analysis as described in our previous study (12). Logarithmic transformation was performed for biomarkers with a right-skewed distribution. Mann-Whitney $U$ and spearman correlation tests were used to investigate the difference or association between two variables when the control of intra-individual variability is not necessary. Otherwise mixed-effect models with random intercepts of participants were used. Particularly, because multiple factors (e.g. passive smoking and behavioral changes) may influence to PAHs exposures simultaneously, we modeled urinary $\mathrm{OH}$-PAHs concentrations as a function of cotinine, year, and questionnaire variables, as well as the interactions of city with cotinine and year. To test the 
associations between biomarkers of exposures and lipid peroxidation, we modeled the concentrations of MDA or 8isoprostane as a function of cotinine or OH-PAHs or both of them in mixed-effect models controlling random effects at both participant and phase levels. Alpha was set at 0.05 , and all tests were two-tailed. Data were analyzed with the statistical software R (www.r-project.org).

\section{Declarations}

Ethics approval and consent to participate. The study was performed in accordance with guidelines and approval of the Institutional Review Board of both UCLA and PKU. Written informed consent were obtained from all participants with study purpose and risk explained.

Consent for publication. All authors consent for publication.

Availability of supporting data. The datasets used during the current study are available from the corresponding author on reasonable request.

Competing interests. The authors declare that they have no competing interests.

Funding. This work was supported by the National Institute of Environmental Health Sciences (NIEHS, 1R21ES024560), the National Natural Science Foundation of China (21876002 and 41561144007), the UCLA center for Occupational and Environmental Health, and the Collaborative Innovation Center for Regional Environmental Quality.

Authors' contributions. YL and $Y Z$ contributed equally. $Y L$ participated in the urine sample and data collection. $Y L$ and $F Y$ performed the laboratory analysis. $Y L$ and $C T$ performed the statistical analysis. $Y L$ and $Y Z$ drafted the manuscript. $Y Z, X Q$, and JAA reviewed and revised the manuscript. JAA, $X Q$, and $Y Z$ designed the current study and supervised all steps.

Acknowledgements. We acknowledge the strong support from all study participants and staff members from the Joint Research Institute in Science and Engineering by Peking University and UCLA.

Authors' information. Not applicable.

\section{References}

1. Sleiman M, Gundel LA, Pankow JF, Jacob P, Singer BC, Destaillats H. Formation of carcinogens indoors by surfacemediated reactions of nicotine with nitrous acid, leading to potential thirdhand smoke hazards. Proc Natl Acad Sci U S A. 2010 Apr 13;107(15):6576-81.

2. Öberg M, Jaakkola MS, Woodward A, Peruga A, Prüss-Ustün A. Worldwide burden of disease from exposure to secondhand smoke: A retrospective analysis of data from 192 countries. Lancet. 2011;377(9760):139-46.

3. Díez-Izquierdo A, Cassanello-Peñarroya P, Lidón-Moyano C, Matilla-Santander N, Balaguer A, Martínez-Sánchez JM. Update on thirdhand smoke: A comprehensive systematic review. Environ Res. 2018;167:341-71.

4. Warren CW, Sinha DN, Lee J, Lea V, Jones NR. Tobacco use, exposure to secondhand smoke, and cessation counseling among medical students: cross-country data from the Global Health Professions Student Survey (GHPSS), 2005-2008. BMC Public Health. 2011;11(1):72.

5. U.S. Centers for Disease Control and Prevention. Exposure to secondhand smoke among students aged 13-15 yearsworldwide, 2000-2007. Morb Mortal Wkly Rep. 2007;56(20):497-500.

6. King BA, Mirza SA, Babb SD. A cross-country comparison of secondhand smoke exposure among adults: findings from the Global Adult Tobacco Survey (GATS). Tob Control. 2013;22(4):e5-5.

7. Thomas S, Fayter D, Misso K, Ogilvie D, Petticrew M, Sowden A, et al. Population tobacco control interventions and their effects on social inequalities in smoking: systematic review. Tob Control. 2008;17(4):230-7. 
8. Ng M, Freeman MK, Fleming TD, Robinson M, Dwyer-Lindgren L, Thomson B, et al. Smoking prevalence and cigarette consumption in 187 countries, 1980-2012. Jama. 2014;311(2):183-92.

9. U.S. Department of Health and Human Services. The Health Consequences of Involuntary Exposure to Tobacco Smoke: A Report of the Surgeon General. 2006.

10. Guo Y, Senthilkumar K, Alomirah H, Moon HB, Minh TB, Mohd MA, et al. Concentrations and profiles of urinary polycyclic aromatic hydrocarbon metabolites (OH-PAHs) in several Asian countries. Environ Sci Technol. 2013;47(6):2932-8.

11. U.S. Department of Commerce ITA Tourism Industries. 2015 Profile of U.S. Resident Traveler Visiting Overseas Destinations Reported From: Survey of International Air Travelers. ITA. Office of Travel \& Tourism Industries.

12. Lin Y, Ramanathan G, Zhu Y, Yin F, Rea ND, Lu X, et al. Pro-Oxidative and Proinflammatory Effects after Traveling from Los Angeles to Beijing: A Biomarker-Based Natural Experiment. Circulation. 2019 Dec;10(24):1995-2004. 140(.

13. Lin Y, Qiu X, Yu NN, Yang Q, Araujo JAJA, Zhu Y. Urinary Metabolites of Polycyclic Aromatic Hydrocarbons and the Association with Lipid Peroxidation: A Biomarker-Based Study between Los Angeles and Beijing. Environ Sci Technol. 2016;50(7):3738-45.

14. Barnoya J, Glantz SA. Cardiovascular effects of secondhand smoke: Nearly as large as smoking. Circulation. 2005;111(20):2684-98.

15. Bernhoft RA. Cadmium toxicity and treatment. Sci World J. 2013;2013.

16. Zhang J, Ou JX, Bai CX. Tobacco smoking in China: Prevalence, disease burden, challenges and future strategies. Respirology. 2011;16(8):1165-72.

17. Benowitz NL. Cotinine as a biomarker of environmental tobacco smoke exposure. Epidemiol Rev. 1996;18(2):188-204.

18. St Helen G, Goniewicz ML, Dempsey D, Wilson M, Jacob P 3rd, Benowitz NL. Exposure and kinetics of polycyclic aromatic hydrocarbons (PAHs) in cigarette smokers. Chem Res Toxicol. 2012;25(4):952-64.

19. Bramer SL, Kallungal BA. Clinical considerations in study designs that use cotinine as a biomarker. Biomarkers. 2003;8(4/3):187-203.

20. Den Hond E, Govarts E, Willems H, Smolders R, Casteleyn L, Kolossa-Gehring M, et al. First steps toward harmonized human biomonitoring in Europe: Demonstration project to perform human biomonitoring on a European scale. Environ Health Perspect. 2015;123(3):255-63.

21. Suwan-ampai P, Navas-Acien A, Strickland PT, Agnew J. Involuntary tobacco smoke exposure and urinary levels of polycyclic aromatic hydrocarbons in the United States, 1999 to 2002. Cancer Epidemiol Biomarkers Prev. 2009;18(3):88493.

22. Kim K-H, Jahan SA, Kabir E, Brown RJC. A review of airborne polycyclic aromatic hydrocarbons (PAHs) and their human health effects. Environ Int. 2013;60:71-80.

23. Eiguren-Fernandez A, Avol EL, Thurairatnam S, Hakami M, Froines JR, Miguel AH. Seasonal influence on vapor- and particle-phase polycyclic aromatic hydrocarbon concentrations in school communities located in Southern California. Aerosol Sci Technol. 2007;41(4):438-46.

24. Ma WL, Sun DZ, Shen WG, Yang M, Qi H, Liu LY, et al. Atmospheric concentrations, sources and gas-particle partitioning of PAHs in Beijing after the 29th Olympic Games. Environ Pollut. 2011;159(7):1794-801.

25. Yu Y, Li Q, Wang H, Wang B, Wang X, Ren A, et al. Risk of human exposure to polycyclic aromatic hydrocarbons: A case study in Beijing, China. Vol. 205, Environmental Pollution. 2015.

26. Zhang Y, Ding J, Shen G, Zhong J, Wang C, Wei S, et al. Dietary and inhalation exposure to polycyclic aromatic hydrocarbons and urinary excretion of monohydroxy metabolites - A controlled case study in Beijing, China. Vol. 184, Environmental Pollution. 2014.

27. Deziel NC, Wei WQ, Abnet CC, Qiao YL, Sunderland D, Ren JS, et al. A multi-day environmental study of polycyclic aromatic hydrocarbon exposure in a high-risk region for esophageal cancer in China. J Expo Sci Environ Epidemiol. 2013;23(1):52-9. 
28. Jakszyn P, Agudo A, Ibáñez R, García-Closas R, Pera G, Amiano P, et al. Development of a food database of nitrosamines, heterocyclic amines, and polycyclic aromatic hydrocarbons. J Nutr. 2004;134:2011-4.

29. Wu X, Lintelmann J, Klingbeil S, Li J, Wang H, Kuhn E, et al. Determination of air pollution-related biomarkers of exposure in urine of travellers between Germany and China using liquid chromatographic and liquid chromatographic-mass spectrometric methods: a pilot study. Biomarkers. 2017;22(6):525-36.

30. Esterbauer H, Wäg G, Puhl H. Lipid peroxidation and its role in atherosclerosis. Br Med Bull. 1993;49(3):566-76.

31. Cigremis Y, Turkoz Y, Akgoz M, Sozmen M. The effects of chronic exposure to ethanol and cigarette smoke on the level of reduced glutathione and malondialdehyde in rat kidney. Urol Res. 2004;32(3):213-8.

32. Pryor WA, Stone K. Oxidants in Cigarette Smoke Radicals, Hydrogen Peroxide, Peroxynitrate, and Peroxynitrite. Ann N Y Acad Sci. 1993;686(1):12-27.

33. Aquilina NJ, Delgado-Saborit JM, Meddings C, Baker S, Harrison RM, Jacob P, et al. Environmental and biological monitoring of exposures to PAHs and ETS in the general population. Environ Int. 2010;36(7):763-71.

34. Mori T, Yoshinaga J, Suzuki K, Mizoi M, Adachi S ichi, Tao H, et al. Exposure to polycyclic aromatic hydrocarbons, arsenic and environmental tobacco smoke, nutrient intake, and oxidative stress in Japanese preschool children. Sci Total Environ. 2011;409(15):2881-7.

35. Joo H, Lim M-H, Ha M, Kwon H-J, Yoo SJ, Choi K-H, et al. Secondhand Smoke Exposure and Low Blood Lead Levels in Association With Attention-Deficit Hyperactivity Disorder and Its Symptom Domain in Children: A Community-Based Case-Control Study. Nicotine Tob Res. 2016;(September):94-101.

36. Tranfo G, Pigini D, Paci E, Marini F, Bonanni RC. Association of exposure to benzene and smoking with oxidative damage to nucleic acids by means of biological monitoring of general population volunteers. Environ Sci Pollut Res.

2017;24(16):13885-94.

37. Zhang D-D, Cao J, Dong Z, Li J-X, Li G, Ma A-J, et al. Prevalence of active and passive tobacco smoking among Beijing residents in 2011. Chronic Dis Transl Med. 2016;2(2):120-8.

38. Los Angeles County Department of Public Health. Cigarette Smoking in Los Angeles County: Local Data to Inform Tobacco Policy. 2010.

39. Demographia World Urban Areas. (15th Annual Edition: 201904). http://www.demographia.com/db-worldua.pdf.

40. Ng M, Freeman MK, Fleming TD, Robinson M, Dwyer-Lindgren L, Thomson B, et al. Smoking Prevalence and Cigarette Consumption in 187 Countries, 1980-2012. Jama. 2014;311(2):183.

41. Orton S, Jones LL, Cooper S, Lewis S, Coleman T. Predictors of children's secondhand smoke exposure at home: A systematic review and narrative synthesis of the evidence. PLoS One. 2014;9(11).

42. Harris Geremakis C, Moreland-Russell S, Carothers BJ, Kariuki B, Shelton SC, Kuhlenbeck MJK. Demographic and geographic differences in exposure to secondhand smoke in\rMissouri workplaces, 2007-2008. Prev Chronic Dis. 2011;8(6):A135.

43. Stillman F, Navas-Acien A, Ma J, Ma S, Avila-Tang E, Breysse P, et al. Second-hand tobacco smoke in public places in urban and rural China. Tob Control. 2007;16(4):229-34.

44. Hammond SK. Exposure of U. S. Workers to Environmental Tobacco Smoke. Env Heal Perspect. 1999;107:329-40.

45. Xiao L, Jiang Y, Liu X, Li Y, Gan Q, Liu F. Smoking reduced in urban restaurants: the effect of Beijing Smoking Control Regulation. Tob Control. 2017;26(e1):e75-8.

46. Lin Y, Qiu X, Liu J, Tseng CH, Allard P, Araujo JA, et al. Different temporal trends of exposure to Bisphenol A among international travelers between Los Angeles and Beijing. Environ Int. 2020;141:105758.

47. Toora BD, Rajagopal G. Measurement of creatinine by Jaffe's reaction-determination of concentration of sodium hydroxide required for maximum color development in standard, urine and protein free filtrate of serum. Indian J Exp Biol. 2002;40(3):352-4.

\section{Figures}

Page $12 / 15$ 

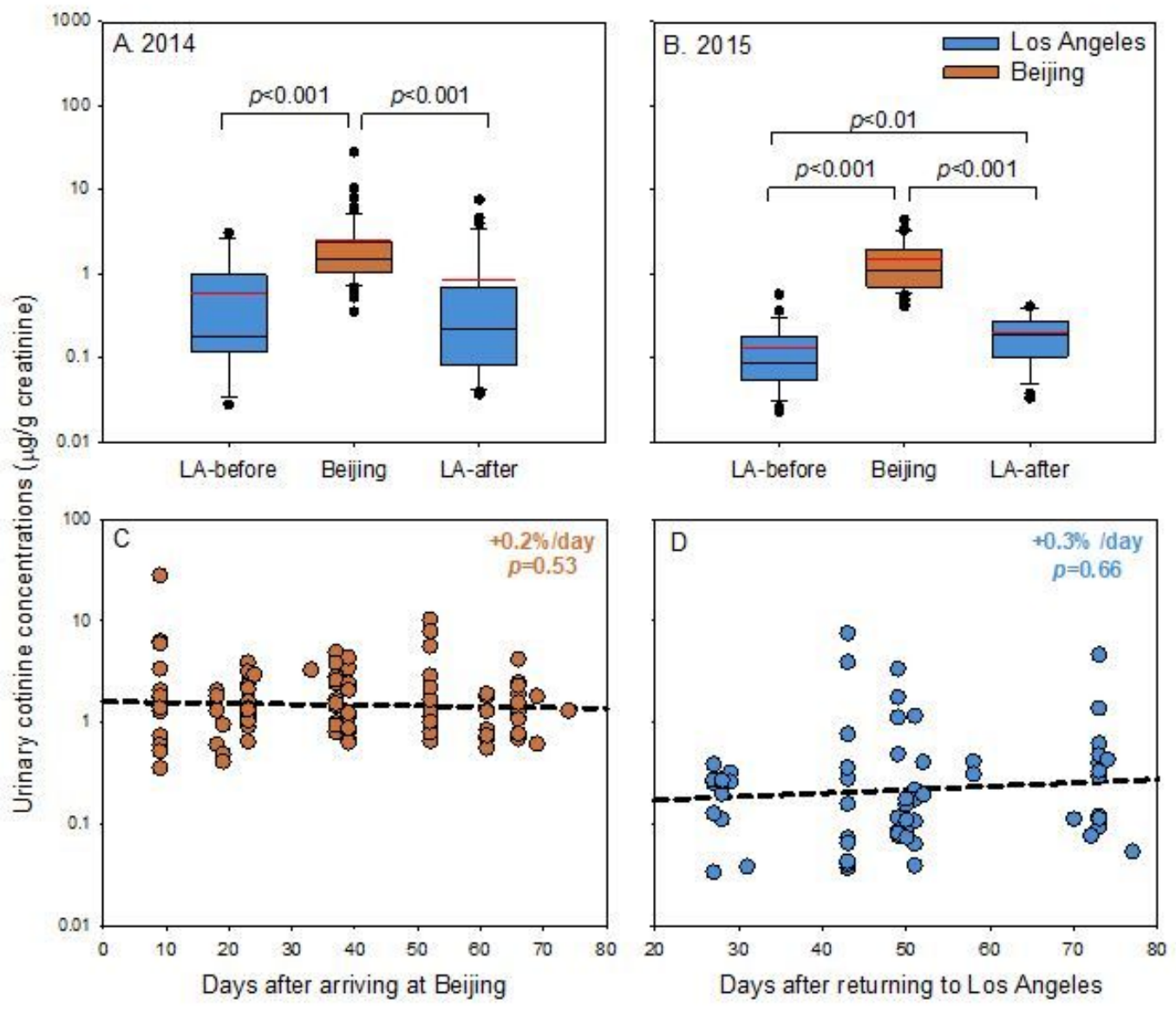

Figure 1

Urinary cotinine concentrations in LA-before, Beijing, and LA-after in 2014 (panel A) and 2015 (panel B), as well as the effects of time lapse in Beijing and LA-after on cotinine concentrations (panels $C$ and D) (blue and orange plots indicate data in Los Angeles and Beijing, respectively; black line - median of each date; red line - mean of each date; box - 25th and75th percentiles; whiskers - 10th and 90th percentiles. Differences in cotinine concentrations between phases and associations between cotinine concentrations and days in a city were tested in mixed-effect models with random intercepts of study participant) 

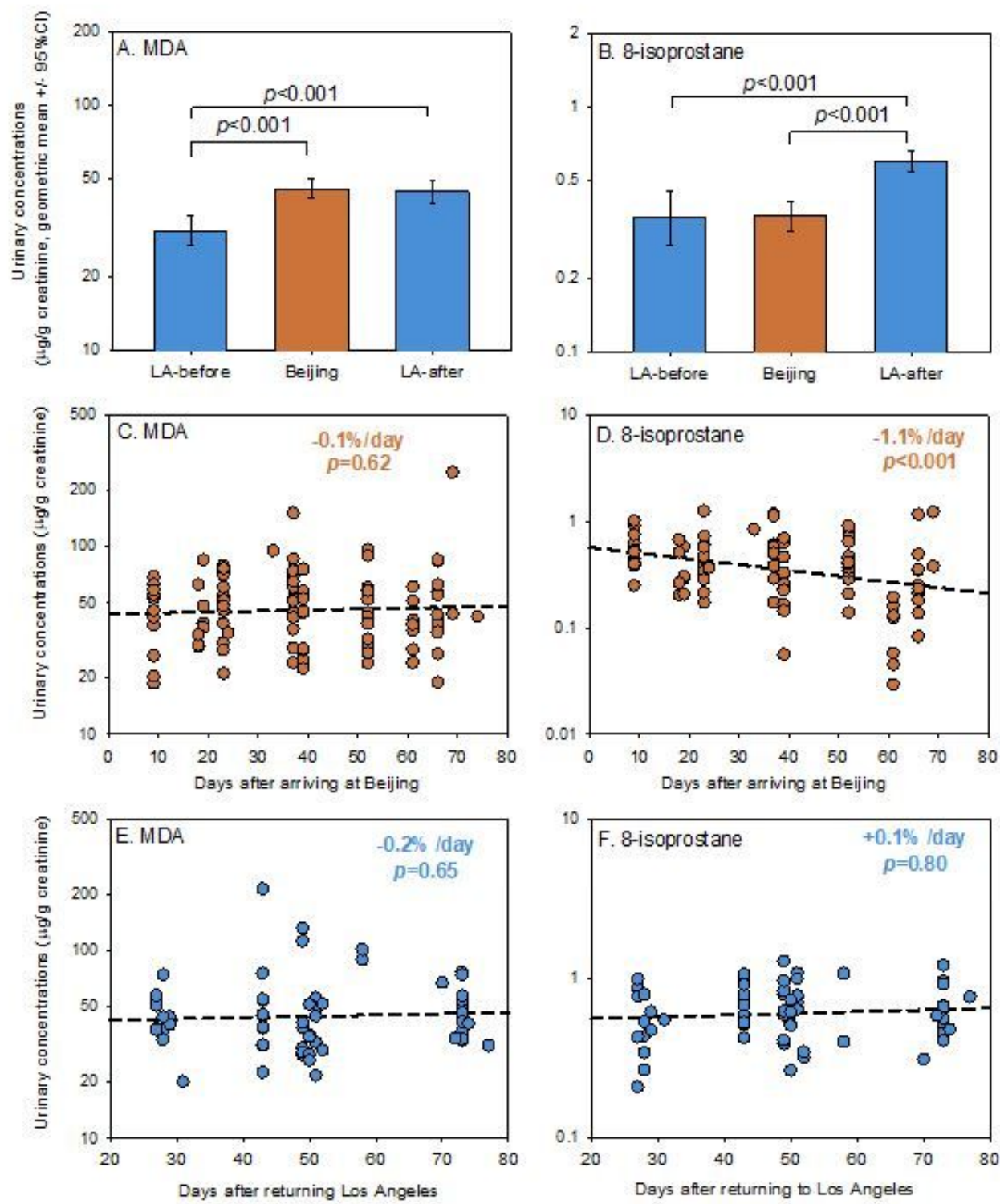

Figure 2

Urinary concentrations of MDA (panel A) and 8-isoprostane (panel B) in LA-before, Beijing, and LA-after, and the effects of time lapse in Beijing (panels $C$ and D) and LA-after (panels $E$ and F) on biomarker concentrations (blue and orange plots indicate data in Los Angeles and Beijing, respectively. Differences in biomarkers concentrations between phases and associations between biomarker concentrations and days in a city were tested in mixed-effect models with random intercepts of study participant.) 

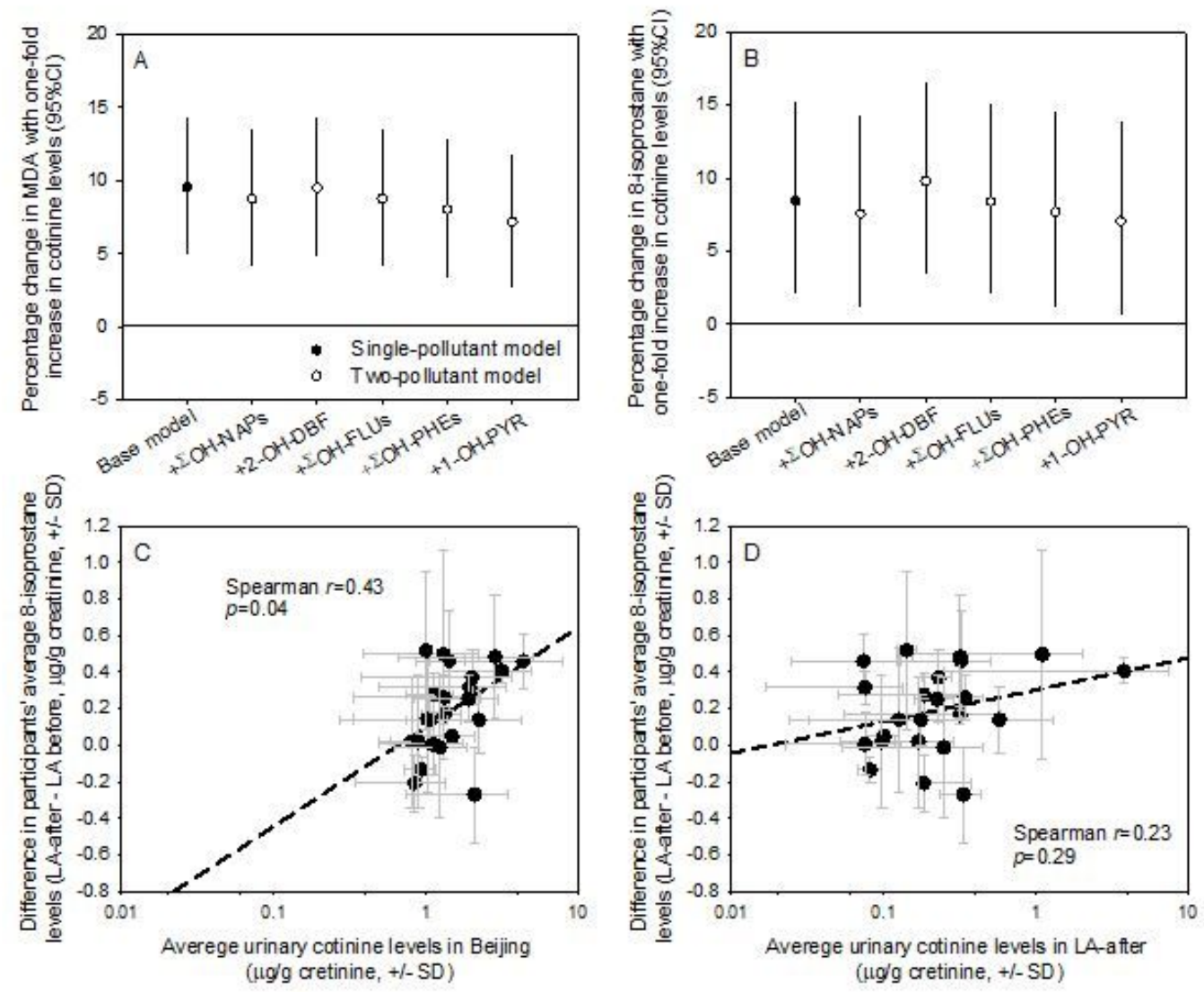

Figure 3

Percentage changes of urinary concentrations of MDA (panel A) and 8-isoprostane (panel B) associated with one-fold increases in urinary cotinine levels in mixed-effect models with random intercepts of study participant and phase; and spearman correlations between increments of 8-isoprostane concentrations in LA-after from LA-before and average cotinine concentrations in Beijing (panel C) and in LA-after (panel D)

\section{Supplementary Files}

This is a list of supplementary files associated with this preprint. Click to download.

- SupplementalMaterialssubmitted.docx

- SupplementalMaterialssubmitted.docx 